\title{
Transfer of Antimicrobial-Resistant Escherichia coli and Resistance Genes in a Child Care Center
}

\author{
Hyunjin Hong ${ }^{1,2}$ and Yeonhee Lee ${ }^{1,2 *}$ \\ ${ }^{1}$ Culture Collection of Antimicrobial Resistant Microbes (CCARM), Seoul 01797, Republic of Korea \\ ${ }^{2}$ Department of Horticulture, Biotechnology, and Landscape Architecture, Seoul Women's University, Seoul 01797, Republic of Korea
}

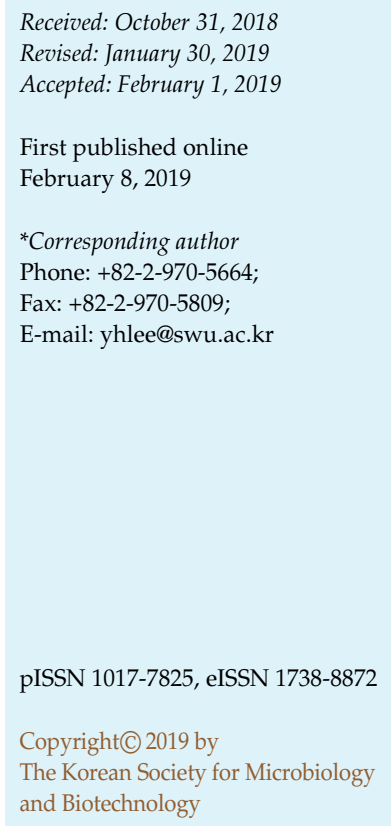

\begin{abstract}
Several reports describe antimicrobial-resistance transfer among children and the community in outbreak situations, but transfer between a child and a caregiver has not been examined in child care facilities under normal circumstances. We investigated the transfer of antimicrobialresistance genes, resistant bacteria, or both among healthy children and teachers. From 2007 to 2009, 104 Escherichia coli isolates were obtained from four teachers and 38 children in a child care center. Twenty-six cephem-resistant isolates were obtained from children in 2007 and 2008. In 2009, cephem-resistant isolates were detected in children as well as a teacher. Nalidixic acid-resistant isolates from the same teacher for 3 years showed low similarity $(<50 \%)$ to each other. However, an isolate from a teacher in 2007 and another from a child in 2008 showed high similarity (87\%). Pulsed-field gel electrophoresis revealed $100 \%$ similarity for four isolates in 2007 and one isolate in 2008, and also similarity among seven isolates carrying the virulence gene (CNF1). This study yielded the following findings: (1) a gene for extended-spectrum $\beta$-lactamase was transferred from a child to other children and a teacher; (2) a nalidixic acid-resistant isolate was transferred from a teacher to a child; and (3) a virulent bacterium was transferred between children.
\end{abstract}

Keywords: Escherichia coli, child care center, antimicrobial resistance, transfer

\section{Introduction}

More than $80 \%$ of urinary tract infections in children are caused by Escherichia coli [1], and approximately $8 \%$ of children from 1 month to 11 years old experience infections from E. coli [2]. As the number of antimicrobial agents to treat E. coli urinary tract infection has increased, the occurrence of resistant bacteria has also increased [3]. Antimicrobial-resistant bacteria can cause a serious health risk, especially in children [4]. Children at a child care facility may play a role as a reservoir of resistant bacteria, and they can transfer resistant bacteria to family and community members, resulting in spread of resistance [46]. Some reports have described higher detection rates of methicillin-resistant Staphylococcus aureus (MRSA) and trimethoprim-resistant $E$. coli in children attending child care facilities than in those who do not attend a child care facility [7-9]. Adcock et al. highlighted that resistant strains are spread to families and communities through person-toperson contact [5]. However, no study has investigated the transfer of antibiotic-resistance genes or antibiotic-resistant bacteria between healthy children and teachers in a child care facility.

Transfer of antimicrobial-resistant bacteria and resistance genes may be a great risk not only to children and teachers, but also to the local community. Therefore, this study aimed to investigate the actual transmission of antibioticresistant bacteria and antibiotic-resistant genes in a child care facility.

\section{Materials and Methods}

Isolation and Identification of $E$. coli

Fecal samples were obtained from four teachers and 38 children (6 to 36 months old) in a child care center in the city of Gwangmyeong, Korea, with sterile cotton swabs and transported 
to the laboratory in a transport medium. E. coli was isolated following the guidelines of Association of Official Analytical Chemists [10]. Samples were inoculated on MacConkey agar plate (BD, France) by streaking. After incubation for $18-24 \mathrm{~h}$ at $35^{\circ} \mathrm{C}$, well-isolated pink colonies were obtained and re-inoculated to obtain pure colonies. Each isolate was identified with API 20E (bioMérieux, France). Isolates were deposited in the Culture Collection of Antimicrobial Resistant Microbes (CCARM, Korea).

\section{Assay of Minimal Inhibitory Concentration}

Minimal inhibitory concentrations (MICs) were assayed with the agar dilution method following the guidelines of the Clinical and Laboratory Standards Institute (CLSI) [11]. Tested antimicrobial agents were ampicillin, cephalothin, cefoxitin, cefazolin, cefotaxime, ceftazidime, chloramphenicol, ciprofloxacin, gentamicin, nalidixic acid, norfloxacin, streptomycin, and tetracycline. In case of nalidixic acid-resistant $E$. coli, response to gatifloxacin, gemifloxacin, levofloxacin, and ofloxacin was also tested. Antimicrobial agents were purchased from Sigma (USA). Escherichia coli ATCC 25922 was used as a control.

\section{Double-Disk Synergy Test}

The double-disk synergy test (DDST) was performed with strains resistant to at least one cephalosporin according to the CLSI guidelines [11]. Muller-Hinton agar (BD) plates and disks containing $30 \mu \mathrm{g}$ of ceftazidime or cefotaxime, with and without $10 \mu \mathrm{g}$ of clavulanic acid, were used for the test. Klebsiella pneumoniae ATCC 700603 was used as a control.

\section{Detection of ESBL Genes by PCR and Sequencing}

PCR with specific primers and sequencing were used to characterize the type of $\beta$-lactamase. PCR primers and conditions have been described previously [12, 13]. PCR was performed in a total volume of $25 \mu \mathrm{l}$, containing $2 \mu \mathrm{l}$ of template DNA, $10 \mathrm{pmol}$ of specific primers, $1.5 \mathrm{U}$ of Taq polymerase, and $200 \mu \mathrm{M}$ each of dATP, dCTP, dGTP, and dTTP (Biobasic, Canada) in a reaction buffer consisting of $100 \mathrm{mM}$ Tris- $\mathrm{HCl}, 500 \mathrm{mM} \mathrm{KCl}$, and $1 \mathrm{mM}$ $\mathrm{MgCl}_{2}$. PCR was performed using GeneAmp PCR system 9700 (Applied Biosystems, USA). After electrophoresis of PCR products on a $1 \%$ agarose gel and visualization with ethidium bromide, the products were purified using the QIAquick Gel Extraction Kit (Qiagen, USA). DNA sequencing was performed with an ABI 3730XL Sequencer (Applied Biosystems) by Bionics (Korea).

\section{Detection of Quinolone-Resistance Mutations}

Mutations in quinolone resistance determining regions (QRDRs) of DNA, including gyrase ( $g y r A$ and $g y r B$ ) and topoisomerase IV (parC and parE), were detected by sequencing the genes after PCR with specific primers $[14,15]$. PCR amplification of $q n r$ and $a a c\left(6^{\prime}\right)-I b-c r$ was performed as described previously [16-18]. PCR was performed in a total volume of $25 \mu \mathrm{l}$, containing $2 \mu \mathrm{l}$ of template DNA, 10 pmol of specific primer, $1.5 \mathrm{U}$ of Taq polymerase, and $200 \mu \mathrm{M}$ each of dATP, dCTP, dGTP, and dTTP (Biobasic) in a reaction buffer consisting of $100 \mathrm{mM}$ Tris- $\mathrm{HCl}, 500 \mathrm{mM} \mathrm{KCl}$, and $1 \mathrm{mM} \mathrm{MgCl}$. PCR was performed using GeneAmp PCR system 9700 (Applied Biosystems). PCR products were treated and sequenced as described for ESBL genes.

\section{Detection of Virulence Genes by PCR}

Multiplex PCR for virulence genes in E. coli was performed with primers specific to 11 virulence genes (VE1)-heat-labile (LTI) and heat-stable (STI, STII) toxin; verotoxin types 1, 2, and 2e (VT1, VT2, and VT2e); cytotoxic necrotizing factor (CNF)1 and CNF2; attaching and effacing mechanisms (eaeA); enteroaggregative mechanisms (Eagg); and enteroinvasive mechanisms (Einv) as previously described [19]. PCR was performed in a total volume of $25 \mu \mathrm{l}$, containing $2 \mu \mathrm{l}$ of template DNA, 10 pmol of specific primer for virulence genes (Table 1), $1.5 \mathrm{U}$ of Taq polymerase, and $200 \mu \mathrm{M}$ each of dATP, dCTP, dGTP, and dTTP (Biobasic, Ontario, Canada) in a reaction buffer consisting of $100 \mathrm{mM}$ Tris- $\mathrm{HCl}$, $500 \mathrm{mM} \mathrm{KCl}$, and $1 \mathrm{mM} \mathrm{MgCl}_{2}$. PCR was performed using GeneAmp PCR system 9700 (Applied Biosystems), and PCR products were visualized with ethidium bromide after electrophoresis on a $1 \%$ agarose gel.

\section{Pulsed-Field Gel Electrophoresis}

Pulsed-field gel electrophoresis (PFGE) was performed as described in a PulseNet with some modifications [20]. Briefly, bacterial cells were grown overnight on Luria Bertani (LB, BD) agar plates at $37^{\circ} \mathrm{C}$. Colonies were suspended in a suspension buffer (100 mM Tris-HCl, 100 mM EDTA, pH 8.0), and cell density was adjusted to $1.3-1.4$ at $610 \mathrm{~nm}$. The cell suspension $(100 \mu \mathrm{l})$ was mixed with $5 \mu \mathrm{l}$ of proteinase $\mathrm{K}(20 \mathrm{mg} / \mathrm{ml})$ and an equal volume of melted $1 \%$ InCert agarose. The mixture was carefully dispensed into a sample mold (Bio-Rad, USA). After solidification, plugs were transferred into 2-ml microcentrifuge tubes containing $1.5 \mathrm{ml}$ of cell lysis buffer (50 mM Tris- $\mathrm{HCl}, 50 \mathrm{mM}$ EDTA, $1 \%$ sarcosyl, $\mathrm{pH} 8.0$ ) and $0.5 \mathrm{mg} / \mathrm{ml}$ of proteinase K. Cells were lysed for $1.5 \mathrm{~h}$ in a water bath with continuous agitation. After lysis, plugs were washed twice with sterile distilled water and four times with TE buffer (10 mM Tris- $\mathrm{HCl}, 1 \mathrm{mM}$ EDTA, $\mathrm{pH}$ 8.0) for 15 min per wash at $54^{\circ} \mathrm{C}$ with gentle shaking. Agarose-embedded DNA was equilibrated in a restriction enzyme buffer for $2 \mathrm{~h}$ at $37^{\circ} \mathrm{C}$. For complete digestion of DNA, $50 \mathrm{U}$ of $\mathrm{Xba \textrm {I }}\left(5^{\prime}\right.$-TCTAGA3'; Takara, Japan) was used. Restricted fragments were separated on a $1.0 \%$ SeaKem gold agarose gel using CHEF-DR III (Bio-Rad) in $0.5 \times$ TBE buffer $(44.5 \mathrm{mM}$ Tris, $44.5 \mathrm{mM}$ boric acid, $1 \mathrm{mM}$ EDTA, pH 8.0). Electrophoresis was performed at $6 \mathrm{~V} / \mathrm{cm}$ for $20 \mathrm{~h}$ with pulse time increasing from 2.2 to $54.2 \mathrm{~s}$. A lambda DNA ladder, composed of $48.5 \mathrm{~kb}$ concatemers (BioLabs, USA), was used as the size standard. Digital images were stored electronically as TIF files and analyzed with GelCompar software (Applied Maths, USA). 
Table 1. Sequences of PCR primers for virulence gene and product size.

\begin{tabular}{|c|c|c|}
\hline Virulence gene & Primers $^{\mathrm{a}}$ & Product size (nucleotides) \\
\hline \multirow[t]{2}{*}{ VT1 } & fp: 5'-ACGTTACAGCGTGTTGCRGGGATC-3' & 121 \\
\hline & bp:5'-TTGCCACAGACTGCGTCAGTRAGG-3' & \\
\hline \multirow[t]{2}{*}{ VT2 } & fp: 5’TGTGGCTGGGTTCGTTAATACGGC-3' & 102 \\
\hline & bp:5'-TCCGTTGTCATGGAAACCGTTGTC-3' & \\
\hline \multirow[t]{2}{*}{ VT2e } & fp: 5'-CCAGAATGTCAGATAACTGGCGAC-3' & 322 \\
\hline & bp:5'-GCTGAGCACTTTGTAACAATGGCTG-3' & \\
\hline \multirow[t]{2}{*}{ eaeA } & fp: 5'-TGAGCGGCTGGCATGAGTCATAC-3' & 241 \\
\hline & bp:5'-TCGATCCCCATCGTCACCAGAGG-3' & \\
\hline \multirow[t]{2}{*}{ CNF1 } & fp: 5'-GGCGACAAATGCAGTATTGCTTGG-3' & 552 \\
\hline & bp:5'-GACGTTGGTTGCGGTAATTTTGGG-3' & \\
\hline \multirow[t]{2}{*}{ CNF2 } & fp: 5'-GTGAGGCTCAACGAGATTATGCACTG-3' & 839 \\
\hline & bp:5'-CCACGCTTCTTCTTCAGTTGTTCCTC-3' & \\
\hline \multirow[t]{2}{*}{ LTI } & fp: 5'-TGGATTCATCATGCACCACAAGG-3' & 360 \\
\hline & bp:5'-CCATTTCTCTTTTGCCTGCCATC-3' & \\
\hline \multirow[t]{2}{*}{ STI } & fp: 5'-TTTCCССТCTTTTAGTCAGTCAACTG-3' & 160 \\
\hline & bp:5'-GGCAGGATTACAACAAAGTTCACAG-3' & \\
\hline \multirow[t]{2}{*}{ STII } & fp: 5'-CССССТCTCTTTTGCACTTCTTTCC-3' & 423 \\
\hline & bp:5'-TGCTCCAGCAGTACCATCTCTAACCC-3' & \\
\hline \multirow[t]{2}{*}{ Einv } & fp: 5'-TGGAAAAACTCAGTGCCTCTGCGG-3' & 140 \\
\hline & bp:5'-TTCTGATGCCTGATGGACCAGGAG-3' & \\
\hline \multirow[t]{2}{*}{ Eagg } & fp: 5'-AGACTCTGGCGAAAGACTGTATC-3' & 194 \\
\hline & bp:5'-ATGGCTGTCTGTAATAGATGAGAAC-3' & \\
\hline
\end{tabular}

${ }^{a} \mathrm{fp}$, forward primer; bp, backward primer; $\mathrm{R}=\mathrm{A}$ and $\mathrm{G}$.

\section{Results}

\section{Isolation and Identification of $E$. coli}

A total of 104 E. coli isolates (14 isolates from four teachers and 90 isolates from 38 children) were obtained from June 2007 to March 2009. Colonies that were produced from the same sample but differed in size or antimicrobial resistance profile were treated as independent isolates.

\section{Minimal Inhibitory Concentration}

Antimicrobial resistance patterns of isolates from children and teachers differed from one another. Isolates from children showed higher resistance rates than those from teachers for ampicillin, cephalothin, cephazolin, cefoxitin, cefotaxim, and streptomycin (Table 2). On the contrary, resistance rates to gentamicin, tetracycline, ciprofloxacin, norfloxaxin, and nalidixic acid were higher in isolates from teachers than those from children (Table 2). $\mathrm{MIC}_{90} \mathrm{~s}$ (minimum inhibitory concentration required to inhibit the growth of $90 \%$ of organisms) showed a pattern similar to the resistance rates. $\mathrm{MIC}_{90} \mathrm{~S}$ for cephalothin, cephazolin, cefoxitin, cefotaxim, ceftazidim, and streptomycin in isolates from children were much higher than those of isolates from teachers. $\mathrm{MIC}_{90} \mathrm{~s}$ for gentamicin, norfloxacin, and nalidixic acid were higher in isolates from teachers than in those from children (Table 3).

Two nalidixic acid-resistant E. coli isolates were detected in teachers only in 2007. In 2008 and 2009, nalidixic acidresistant E. coli isolates were detected in six children. Cephalothin- and cephazolin-resistant E. coli were detected in children in 2007 and 2008 but not in 2009 while they were detected in teachers in 2009 (Table 2). Nalidixic acidresistant isolates, CCARM 1F561 from a teacher and CCARM 1F601 and 1F620 from two children showed the same MICs to an additional four quinolones- gatifloxacin, gemifloxacin, levofloxacin, and ofloxacin. However, CCARM 1F561 was susceptible to aminoglycosides and tetracycline, but CCARM 1F601 and 1F620 were resistant to aminoglycosides and tetracycline. 
Table 2. Resistance rate of $E$. coli isolated from a child care center.

\begin{tabular}{|c|c|c|c|c|c|c|c|c|c|}
\hline \multirow{2}{*}{$\begin{array}{c}\text { Class and } \\
\text { antimicrobial agent }\end{array}$} & \multicolumn{2}{|c|}{2007} & \multicolumn{2}{|c|}{2008} & \multicolumn{2}{|c|}{2009} & \multicolumn{3}{|c|}{ Total } \\
\hline & $\begin{array}{l}\text { Teacher } \\
(n=10)^{a}\end{array}$ & $\begin{array}{l}\text { Child } \\
(n=44)\end{array}$ & $\begin{array}{c}\text { Teacher } \\
(n=2)\end{array}$ & $\begin{array}{l}\text { Child } \\
(n=21)\end{array}$ & $\begin{array}{c}\text { Teacher } \\
(n=2)\end{array}$ & $\begin{array}{l}\text { Child } \\
(n=25)\end{array}$ & $\begin{array}{l}\text { Teacher } \\
(n=14)\end{array}$ & $\begin{array}{l}\text { Child } \\
(n=90)\end{array}$ & $\begin{array}{c}\text { Total } \\
(n=104)\end{array}$ \\
\hline \multicolumn{10}{|l|}{ Penicillin } \\
\hline Ampicillin & $4(40.0)^{b}$ & $23(52.3)$ & $1(50.0)$ & $13(61.9)$ & $1(50.0)$ & $15(60.0)$ & $6(42.9)$ & $51(56.7)$ & $57(54.8)$ \\
\hline \multicolumn{10}{|l|}{ Cephem } \\
\hline Cephalothin & $0(0.0)$ & $10(22.7)$ & $0(0.0)$ & $6(28.6)$ & $1(50.0)$ & $10(40.0)$ & $1(7.1)$ & $26(28.9)$ & $27(26.0)$ \\
\hline Cefazoline & $0(0.0)$ & $5(11.4)$ & $0(0.0)$ & $2(9.5)$ & $1(50.0)$ & $6(24.0)$ & $1(7.1)$ & $13(14.4)$ & $14(13.5)$ \\
\hline Cefoxitin & $0(0.0)$ & $2(4.5)$ & $0(0.0)$ & $3(14.3)$ & $0(0.0)$ & $0(0.0)$ & $0(0.0)$ & $5(5.6)$ & $5(4.8)$ \\
\hline Cefotaxime & $0(0.0)$ & $0(0.0)$ & $0(0.0)$ & $1(4.8)$ & $0(0.0)$ & $4(16.0)$ & $0(0.0)$ & $5(5.6)$ & $5(4.8)$ \\
\hline Ceftazidime & $0(0.0)$ & $0(0.0)$ & $0(0.0)$ & $0(0.0)$ & $0(0.0)$ & $0(0.0)$ & $0(0.0)$ & $0(0.0)$ & $0(0.0)$ \\
\hline \multicolumn{10}{|l|}{ Aminoglycoside } \\
\hline Gentamicin & $0(0.0)$ & $0(0.0)$ & $1(50.0)$ & $3(14.3)$ & $1(50.0)$ & $1(4.0)$ & $2(14.3)$ & $4(4.4)$ & $6(5.8)$ \\
\hline Streptomycin & $1(10.0)$ & $5(11.4)$ & $0(0.0)$ & $2(9.5)$ & $0(0.0)$ & $6(24.0)$ & $1(7.1)$ & $13(14.4)$ & $14(13.5)$ \\
\hline \multicolumn{10}{|l|}{ Tetracycline } \\
\hline Tetracycline & $3(30.0)$ & $9(20.5)$ & $1(50.0)$ & $8(38.1)$ & $1(50.0)$ & $10(40.0)$ & $5(35.7)$ & $27(30.3)$ & $32(30.8)$ \\
\hline \multicolumn{10}{|l|}{ Fluoroquinolone } \\
\hline Ciprofloxacin & $1(10.0)$ & $0(0.0)$ & $0(0.0)$ & $2(9.5)$ & $0(0.0)$ & $0(0.0)$ & $1(7.1)$ & $2(2.2)$ & $3(2.9)$ \\
\hline Norfloxacin & $1(10.0)$ & $0(0.0)$ & $0(0.0)$ & $2(9.5)$ & $0(0.0)$ & $0(0.0)$ & $1(7.1)$ & $2(2.2)$ & $3(2.9)$ \\
\hline \multicolumn{10}{|l|}{ Quinolone } \\
\hline Nalidixic acid & $2(20.0)$ & $0(0.0)$ & $1(50.0)$ & $5(23.8)$ & $1(50.0)$ & $1(4.0)$ & $4(28.6)$ & $6(6.7)$ & $10(9.6)$ \\
\hline \multicolumn{10}{|l|}{ Phenicol } \\
\hline Chloramphenicol & $0(0.0)$ & $0(0.0)$ & $0(0.0)$ & $0(0.0)$ & $0(0.0)$ & $0(0.0)$ & $0(0.0)$ & $0(0.0)$ & $0(0.0)$ \\
\hline
\end{tabular}

${ }^{a}$ Number of E. coli isolates.

${ }^{\mathrm{b}}$ Values in parentheses are percentages.

\section{Detection of ESBL Genes}

Eight isolates were identified as ESBL-producing strains by DDST, and all had TEM-type ESBL genes. These isolates included one isolate from a child in 2008 and seven isolates from a teacher and children in 2009.

\section{Quinolone-Resistance Mechanisms and Genotypic Similarity of Nalidixic Acid-Resistant E. coli}

E. coli ten isolates were resistant to nalidixic acid during the 3-year study period. In 2007, two isolates (CCARM 1F561 and 1F572) from teachers were resistant to nalidixic acid. In 2008 and 2009, nalidixic acid-resistant isolates were found in the same teacher as well as in children. These isolates had mutations previously reported in gyr $A$, parC, and parE $[14,15,21-23]$, but not in $g y r B$. In the case of CCARM 1F572, a new mutation was found at gyrA (Pro126 to Leu). CCARM 1F601 and 1F620 had the same MICs and the same mutations in gryA and parC (Table 4). CCARM 1F561 from a teacher and CCARM 1F601 from a child had the same four mutations (two in gyrA and two in parC), while CCARM 1F561 from a teacher and 1F620 from a child had the same five mutations (two in gyrA, two in parC, and one in parE). CCARM 1F615 and 1G123 from two children had the same mutations (one in gyrA and two in parE; Table 4). The $q n r$ and $a a c\left(6^{\prime}\right)-I b$-cr gene were not detected in nalidixic acid-resistant isolates.

\section{Detection of Virulence Genes in E. coli}

Virulence genes were detected in seven isolates from children, and these were all CNF1. These isolates included six isolates in 2007 and one in 2008.

\section{Pulsed-Field Gel Electrophoresis}

High similarity was revealed by PFGE among ESBLproducing isolates, which were all from children (Fig. 1A). CCARM 1 G112 showed close similarity (100\%) to CCARM 1G125, while CCARM 1G124 showed close similarity (96.3\%) to CCARM 1G126. Nalidixic acid-resistant isolates showed close similarity to each other in PFGE (Fig. 1B). CCARM 1F561 from a teacher showed high similarity with 
Table 3. $\mathrm{MIC}_{50}$ and $\mathrm{MIC}_{90}$ of E. coli isolated from a child care center.

\begin{tabular}{|c|c|c|c|c|}
\hline \multirow{2}{*}{$\begin{array}{c}\text { Class and } \\
\text { antimicrobial agent }\end{array}$} & \multicolumn{2}{|c|}{ Teachers $(n=14)$} & \multicolumn{2}{|c|}{ Children $(n=90)$} \\
\hline & $\mathrm{MIC}_{50}$ & $\mathrm{MIC}_{90}$ & $\mathrm{MIC}_{50}$ & $\mathrm{MIC}_{90}$ \\
\hline \multicolumn{5}{|l|}{ Penicillin } \\
\hline Ampicillin & 8 & $>128$ & 32 & $>128$ \\
\hline \multicolumn{5}{|l|}{ Cephems } \\
\hline Cephalothin & 8 & 16 & 8 & $>128$ \\
\hline Cefazoline & 2 & 8 & 4 & $>128$ \\
\hline Cefoxitin & 4 & 4 & 4 & 8 \\
\hline Cefotaxime & $\leq 0.5$ & $\leq 0.5$ & $\leq 0.5$ & 1 \\
\hline Ceftazidime & $\leq 0.5$ & $\leq 0.5$ & $\leq 0.5$ & 1 \\
\hline \multicolumn{5}{|l|}{ Aminoglycosides } \\
\hline Gentamicin & 1 & 64 & 1 & 1 \\
\hline Streptomycin & 8 & 16 & 4 & 128 \\
\hline \multicolumn{5}{|l|}{ Tetracyclines } \\
\hline Tetracycline & 1 & 128 & 1 & 128 \\
\hline \multicolumn{5}{|l|}{ Fluoroquinolones } \\
\hline Ciprofloxacin & $\leq 0.5$ & $\leq 0.5$ & $\leq 0.5$ & $\leq 0.5$ \\
\hline Norfloxacin & $\leq 0.5$ & 1 & $\leq 0.5$ & $\leq 0.5$ \\
\hline \multicolumn{5}{|l|}{ Quinolone } \\
\hline Nalidixic acid & 4 & 128 & 4 & 4 \\
\hline \multicolumn{5}{|l|}{ Phenicols } \\
\hline Chloramphenicol & 8 & 8 & 8 & 8 \\
\hline
\end{tabular}

CCARM 1F602 (87.5\%) and CCARM 1F620 (85.8\%) from children. CCARM 1F615 and CCARM 1G123 from children showed very high similarity $(92.3 \%)$ to each other. In addition, five CNF-producing isolates from children showed 100\% similarity to each other (Fig. 1C).

\section{Discussion}

Children spend considerable time in day care facilities, where they can be easily exposed to various bacteria, and can be reservoirs for antimicrobial-resistant bacteria amplifying the spread of these bacteria in the community [4-6]. If children carry resistant bacteria, treating infection with antimicrobial agents would be difficult.

In Japan, many children in day care facilities frequently experience acute respiratory infection and otitis media. The percentage of children in day care facilities who carry the four major pathogens (Streptococcus pneumoniae, Hemophilus influenzae, Mycobacterium catarrhalis, and S. aureus) is higher than among children who do not attend day care facilities [6]. Adcock (1998) [5] and Carvalho (2017) [9] also reported the possibility of transmission of MRSA to other children in the same facility as well as to their parents. Many studies have reported the transfer of infectious disease among children or children and teachers. However, no report has provided direct evidence of transfer of antimicrobialresistance genes or antimicrobial-resistant bacteria, yet.

Table 4. Mutations detected in the DNA topoisomerase genes of E. coli.

\begin{tabular}{|c|c|c|c|c|c|c|c|c|}
\hline \multirow{2}{*}{ Strain no. } & \multirow{2}{*}{ Year } & & \multicolumn{2}{|c|}{ gyrA } & \multicolumn{2}{|c|}{ parC } & \multicolumn{2}{|c|}{ parE } \\
\hline & & & Amino acid & Substitution & Amino acid & Substitution & Amino acid & Substitution \\
\hline \multirow[t]{2}{*}{ 1F561 } & 2007 & Teacher-HSE & Ser83 & Leu & Ser80 & Ile & Ile529 & Leu \\
\hline & & & Asp87 & Asn & Glu84 & Val & & \\
\hline \multirow[t]{2}{*}{ 1F572 } & 2007 & Teacher-LSH & Ser83 & Leu & & & & \\
\hline & & & Pro126 & Leu & & & & \\
\hline \multirow[t]{2}{*}{ 1F601 } & 2008 & Child-PHJ & Ser83 & Leu & Ser80 & Ile & & \\
\hline & & & Asp87 & Asn & Glu84 & Val & & \\
\hline 1F613 & 2008 & Teacher-HSE & Ser83 & Leu & & & Ile529 & Leu \\
\hline \multirow[t]{2}{*}{$1 \mathrm{~F} 615$} & 2008 & Child-KSJ & Ser83 & Leu & & & Ser458 & Ala \\
\hline & & & & & & & Ile529 & Leu \\
\hline 1F619 & 2008 & Child-YCM & Ser83 & Leu & & & & \\
\hline \multirow[t]{2}{*}{ 1F620 } & 2008 & Child-KDH & Ser83 & Leu & Ser80 & Ile & Ile529 & Leu \\
\hline & & & Asp87 & Asn & Glu84 & Val & & \\
\hline 1F628 & 2008 & Child-WWB & Ser83 & Leu & & & & \\
\hline \multirow[t]{2}{*}{$1 \mathrm{G} 123$} & 2009 & Child-YCS & Ser83 & Leu & & & Ser458 & Ala \\
\hline & & & & & & & Ile529 & Leu \\
\hline $1 G 130$ & 2009 & Teacher-HSE & Ser83 & Leu & & & & \\
\hline
\end{tabular}

Bold, new mutation in gyrA 
A Dice (0p 1;1.00\%) (Tol 1.0\%-1.0\%) (H>0.0\% S>0.0\%) [0.0\%-100.0\%] ESBL E. coli

赵
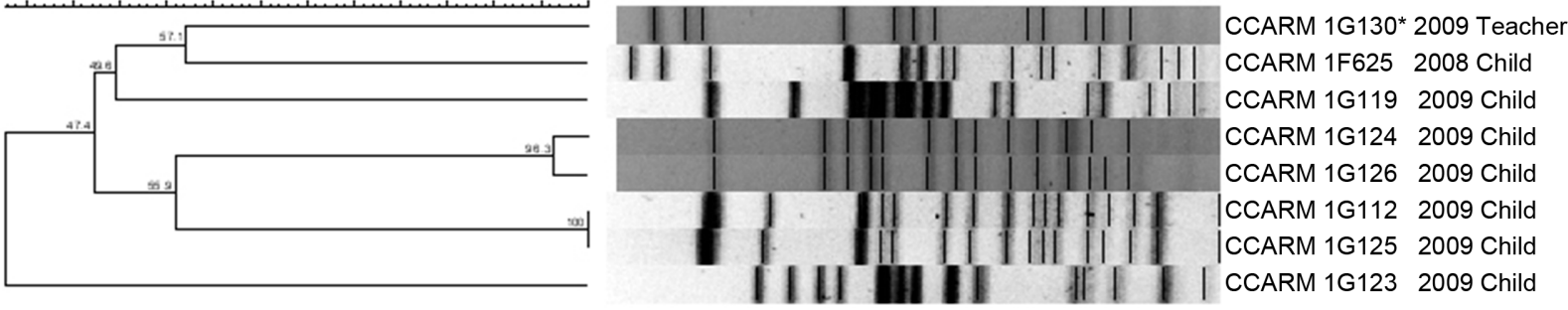

B DICe (0p 1; 1.00\%) (TOl 1.0\%-1.0\%) (H>0.0\% S>0.0\%) [0.0\%-100.0\%] NAL R E. coli
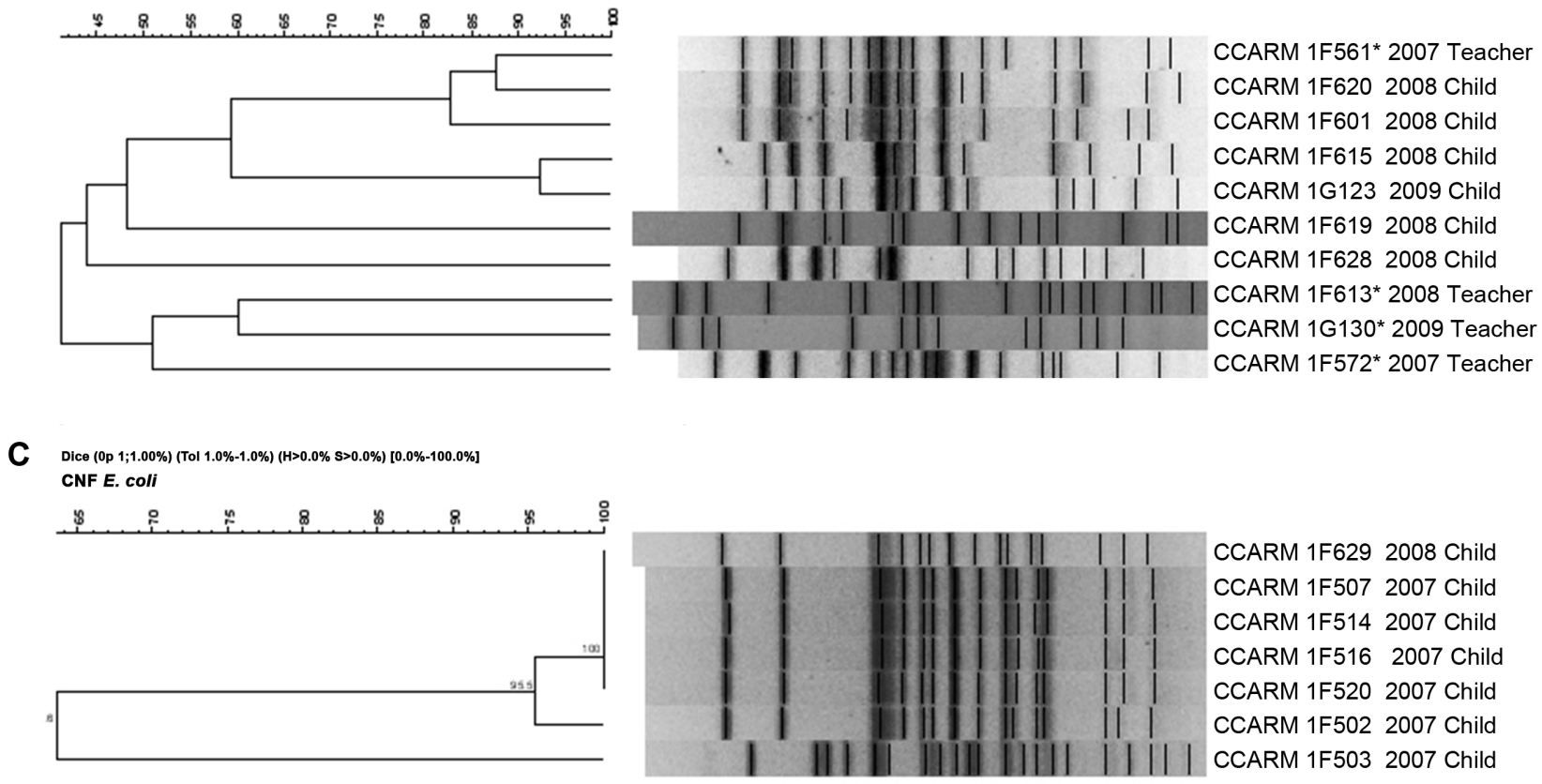

CCARM 1 F629 2008 Child CCARM 1F507 2007 Child CCARM 1F514 2007 Child CCARM $1 F 5162007$ Child CCARM 1F520 2007 Child CCARM 1F502 2007 Child CCARM 1F503 2007 Child

Fig. 1. Dendrogram of E. coli isolates based on PFGE profiles of XbaI-digested genomic DNA using DNA Gel-compar software. (A) ESBL-producing isolates; (B) nalidixic acid-resistant isolates; (C) CNF-producing isolates.

Results of this study showed different antimicrobial resistance patterns of isolates from children and teachers. For example, isolates from children were more resistant to cephem, while isolates from teachers were more resistant to quinolones. This pattern may be due to the different kinds of antimicrobials prescribed for children and adults. Higher resistance rates were observed in isolates from children for antimicrobial agents (cephem) that are generally prescribed to children. Resistance to nalidixic acid, which is no longer prescribed in the clinical environment, was not observed in children. These results support the previous hypothesis that greater use of antimicrobial agents causes more resistance [24, 25].

Quinolone resistance is mediated by mutation of QRDR region $[14,18,26]$, qnr gene for plasmid-borne quinolone resistance $[17,26]$, modification of $a a c\left(6^{\prime}\right)-I b-c r$ gene $[16$, $26]$, and regulation of gene expression of efflux pumps [14, 26]. In this study, we detected QRDR mutation and genes for resistance mechanisms except efflux mechanism.

Nalidixic acid-resistant isolates were first observed in a teacher in 2007, and then in the same teacher and in children in 2008 and 2009. The isolate from a teacher in 2007 (CCARM 1F561) and the isolate from a child in 2008 (CCARM 1F620) had close similarity (87\%) based on PFGE as well as the same point mutations in $g y r A$, parC, and parE. Moreover, these two isolates had the same MICs to 11 antimicrobials, with the exception of aminoglycosides. CCARM 1F620 had much higher MICs to aminoglycosides 
than CCARM 1F561. These results suggest that CCARM 1F561 was transferred to a child and then acquired resistance to aminoglycosides. Aminoglycosides are widely prescribed to children for urinary tract infection, septicemia, and skin and bone soft tissue infection (including ambustion) $[27,28]$ and serve as first-line treatments for unidentified infection. Although they carry risks for nephrotoxicity and ototoxicity, aminoglycosides are widely prescribed because of their useful antimicrobial activity and low cost. These factors make aminoglycosides as the first choice of antimicrobials for ear infection and bronchitis [29].

Close similarities were observed among ESBL-producing isolates from children and teachers in different years. ESBL-producing isolates were detected only in children in 2008 but in both children and teachers in 2009. Among these, two isolates in 2009 (CCARM 1G112 and 1G125) showed $100 \%$ similarity by PFGE and the other two isolates in 2009 (1G124 and 1G126) showed 97\% similarity. Except these four isolates, the other isolates showed no similarity. Since all eight ESBL-producing isolates had the same type ESBL-TEM, the gene, not the bacteria, must have been transferred among children and teachers. Results suggested that nalidixic acid-resistant E. coli was transferred from teachers to children, while cephalothin and cefazolineresistant $E$. coli was transferred among children.

We also investigated the transfer of virulent bacteria and virulence genes. Close similarities were observed among seven isolates with the virulence gene CNF1 from children in 2007 and 2008 as well as among quinolone-resistant isolates from a child and a teacher. CNF1 was detected in isolates from children in 2007 as well as 2008. This result showed the transfer of virulent bacteria as well as a virulence gene.

A monitoring system as well as thorough hygiene practices must be performed to prevent the transfer of resistant bacteria from child care providers to children or between children.

\section{Acknowledgments}

This work was supported by a special grant from Seoul Women's University (2019).

\section{Conflict of Interest}

The authors have no financial conflicts of interest to declare.

\section{References}

1. Borsari AG, Bucher B, Brazzola P, Simonetti GD, Dolina M, Bianchetti MG. 2008. Susceptibility of Escherichia coli strains isolated from outpatient children with community-acquired urinary tract infection in southern Switzerland. Clin. Ther. 30: 2090-2095.

2. Kõljalg S, Truusalu K, Vainumäe I, Stsepetova J, Sepp E, Mikelsaar M. 2009. Persistence of Escherichia coli clones and phenotypic and genotypic antibiotic resistance in recurrent urinary tract infections in childhood. J. Clin. Microbiol. 47: 99-105.

3. Kim S, Yoo R, Lee J. 2015. The impact of the antibiotic burden on the selection of its resistance among gram negative bacteria isolated from children. Pediatr. Infect. Vaccine. 22: 178-185.

4. Holmes SJ, Morrow AL, Pickering LK. 1996. Child-care practices: effects of social change on the epidemiology of infectious diseases and antibiotic resistance. Epidermiol. Rev. 18: 10-28.

5. Adcock PM, Pastor P, Medley F, Patterson JE, Murphy TV. 1998. Methicillin-resistant Staphylococcus aureus in two child care centers. J. Infect Dis. 178: 577-580.

6. Masuda K, Masuda R, Nishi J, Tokuda K, Yoshinaga M, Miyata K. 2002. Incidences of nasopharyngeal colonization of respiratory bacterial pathogens in Japanese children attending day-care centers. Pediatr. Int. 44: 376-380.

7. Reves RR, Fong M, Pickering LK, Bartlett A, Alvarez M, Murray BE. 1990. Risk factors for fecal colonization with trimethoprim-resistant and multiresistant Escherichia coli among children in day-care centers in Houston, Texas. Antimicrob. Agents Chemother. 34: 1429-1434.

8. Lee J, Sung JY, Kim YM, Oh CE, Kim HB, Choi EH, et al. 2011. Molecular characterization of methicillin-resistant Staphylococcus aureus obtained from the anterior nares of healthy Korean children attending daycare centers. Int. J. Infect. Dis. 15: e558-e563.

9. Carvalho SP, Almeida JB, Andrade YMFS, Silva LSCD, Oliveira AC, Nascimento FS, et al. 2017. Communityacquired methicillin-resistant Staphylococcus aureus carrying SCCmec type IV and V isolated from healthy children attending public daycares in northeastern Brazil. Braz. J. Infect. Dis. 21: 464-467.

10. AOAC International. 1997. Official Methods of Analysis, pp. 1.01-13.23. $15^{\text {th }}$ ed. Association of Official Analytical Chemists, Washington. DC.

11. Clinical and Laboratory Standards Institute. 2014. Performance standards for antimicrobial susceptibility testing; twentyfourth informational supplement. CLSI, Wayne, PA.1

12. Oliver A, Perez-Diaz JC, Coque TM, Baquero F, Cantón R. 2001. Nucleotide sequence and characterization of a novel cefotaxime-hydrolyzing $\beta$-lactamase (CTX-M-10). Antimicrob. Agents Chemother. 45: 612-20. 
13. Coque TM, Oliver A, Perez-Diaz JC, Baquero F, Cantón R. 2002. Genes encoding TEM-4, SHV-2 and CTXM-10 extendedspectrum $\beta$-lactamases are carried by multiple Klebsiella pneumoniae clones in a single hospital (Madrid, 1989 to 2000). Antimicrob. Agents Chemother. 46: 500-510.

14. Jung $Y$, Hong $H$, Nam $H$, Lee $Y$. 2002. Isolation of norfloxacin resistant Escherichia coli from the Han-river and characterization of resistance mechanism. J. Microbiol. 40: 63-69.

15. Guerra B, Malorny B, Schroeter A, Helmuth R. 2003. Multiple resistance mechanisms in fluoroquinolone-resistant Salmonella isolates from Germany. Antimicrob. Agents Chemother. 47: 2059.

16. Park CH, Robicsek A, Jacoby GA, Sahm D, Hooper DC. 2006. Prevalence in the United States of aac $\left(6^{\prime}\right)$-Ib-cr encoding a ciprofloxacin-modifying enzyme. Antimicrob. Agents Chemother. 50: 3953-3955.

17. Robicsek A, Strahilevitz J, Sahm DF, Jacoby GA, Hopper DC. 2006. $q n r$ prevalence in cefrazidime-resistant Enteronacteriaceae isolates from, the United States. Antimicrob. Agents Chemother. 50: 2872-2874.

18. Moon DC, Seol SY, Gurung M, Jin JS, Choi CH, Kim J, et al. 2010. Emergence of a new mutation and its accumulation in the topoisomerase IV gene confers high levels of resistance to fluoroquinolones in Escherichia coli isolates. Int. J. Antimicrob. Agents. 35: 76-79.

19. Pass MA, Odedra R, Batt RM. 2000. Multiplex PCRs for identification of Escherichia coli virulence genes. J. Clin. Microbiol. 38: 2001-2004.

20. Swaminathan B, Barrett TJ, Hunter SB, Tauxe RV. 2001. PulseNet: the molecular subtyping network for foodborne bacterial disease surveillance, United States. Emerg. Infect. Dis. 7: 382-389.

21. Jung D, Lee MY, Kim JM, Lee JC, Cho DT, Lee Y. 2006. Isolation of quinolone-resistant Escherichia coli found in major rivers in Korea. J. Microbiol. 44: 680-684.

22. Adachi F, Yamamoto A, Takakura K, Kawahara R. 2013. Occurrence of fluoroquinolones and fluoroquinolone-resistant genes in the aquatic environment. Sci. Total Environ. 444: 508-514.

23. Paltansing S, Kraakman ME, Ras JM, Wessels E, Bernards AT. 2013. Characterization of fluorquinolone and cephalosporin resistance mechanisms in Enterobacteriaceae isolated in a Dutch teaching hospital reveals the presence of an Escherichia coli ST131 clone with a specific mutation on parE. J. Antimicrob. Chemother. 68: 40-45.

24. McEwen SA, Fedorka-Cray PJ. 2002. Antimicrobial use and resistance in animals. Clin. Infect. Dis. 34: S93-S106.

25. Chong Y, Lee K. 2000. Present situation of antimicrobial resistance in Korea. J. Infect. Chemother. 6: 189-195.

26. Jacoby GA. 2005. Mechanisms of resistance to quinolones. Clin. Infect. Dis. 41: S120-S126.

27. Shin SH. 2008. Once daily dosing of aminoglycoside in children. Korean J. Pediatr. 51: 1038-1041.

28. Jang BW. 2011. Information on proper use of medicines for children. Ministry of Food and Drug Safety.

29. Byun JY. 2012. Update of research on aminoglycoside ototoxicity. Korean J. Otorhinolaryngol-Head Neck Surg. 55: 1-7. 